\title{
ORGANIZACIÓN ADMINISTRATIVA Y RELACIONES INTERADMINISTRATIVAS
}

\author{
Antonio Jiménez-Blanco Carrillo de Albornoz \\ Catedrático de Derecho Administrativo de la Universidad Politécnica de Madrid \\ anjibl@telefonica.net
}

\section{PRESENTACIÓN}

Como es notorio, la concreta materia de la que estamos hablando se encuentra regulada en diferentes lugares. En sus líneas básicas, nada menos que en la propia Constitución. El Art. 103 proclama los principios de jerarquía, descentralización, desconcentración y coordinación. El Art. 145 regula los (sospechosos) Convenios entre Comunidades Autónomas y también los (inocentes) Acuerdos de Cooperación. El Art. 149.1, al enumerar las competencias exclusivas del Estado, vuelve a emplear varias veces la palabra coordinación. Y el Art. 154 atribuye al Delegado del Gobierno la función de coordinar la Administración propia -la estatal- con la de la Comunidad Autónoma.

Y luego está sobre todo la LRJ-PAC de 1992, reformada (poco a los efectos que nos conciernen) en 1999 y 2009. De la Organización se ocupa sobre todo el Título II, precisamente así llamado, que comprende los Arts. 11 a 29.

Y antes está el Título I, De las Administraciones Públicas y sus relaciones, con el siguiente (y muy famoso) contenido:

- Art. 4, Principios de las relaciones entre las Administraciones Públicas.

- Art. 5, Conferencias sectoriales y otros órganos de cooperación.

- Art. 6, Convenios de colaboración.

- Art. 7, Planes y programas conjuntos.

- Art. 8, Eficacia de los Convenios.

- Art. 9, Relaciones con la Administración Local. Con reenvío a la Ley 7/1985, de 2 de abril, reguladora de las bases del régimen local (Arts. 55 a 61).

- Art. 10, Comunicaciones a las Comunidad Europeas.

El contenido de dicho Título I de la Ley de 1992 merece, por supuesto, un amplio comentario, sobre todo por aquello que no dice: las relaciones con Europa, que ya en aquel tiempo, seis años después de la adhesión a la entonces llamada CEE, eran muy importantes. A la citada Ley le era reprochable haber visto a España como poco menos que un convento de clausura (repleto, eso sí, de Administraciones, porque lo nuestro, como buen país del barroco, es el horror vacui: ni un solo palmo cuadrado de terreno sin un funcionario y un político), siendo así que, sin embargo, ya para entonces no éramos -felizmente- sino una pieza dentro de un engranaje mayor. El Art. 10 sólo contemplaba un aspecto muy parcial de esa realidad transnacional y lo mismo puede decirse del Art. 42. Una visión que se explica, como es obvio, porque el autor del texto legal sólo tenía en la cabeza las covachuelas burocráticas donde se tratan uno a uno los expedientes -una sanción al enemigo, una licencia o tal o cual gabela al amiguete-, no la Administración directiva y ordenadora, que es la que más importa y la que, sobre todo en las áreas económicas, está en permanente contacto con Europa hasta el grado de que en muchas ocasiones funge como poco más que una dependencia de Bruselas.

Ese es el punto de partida desde la perspectiva legislativa, por así decir. 
El Proyecto de Ley de Régimen Jurídico del Sector Público (PLRJSP) cuenta, como, es sabido, con cuatro Títulos, a saber:

- Preliminar: Disposiciones Generales, principios de actuación y funcionamiento del sector público. Son los Arts. 1 a 28.

- I: Administración General del Estado. Arts. 29 a 55

- II: Organización y funcionamiento del sector público institucional. Arts. 56 a 114.

- III: Relaciones interadministrativas. Arts. 115 a 133.

Más Disposiciones Adicionales (18), Transitorias (2), Derogatoria (Única) y Finales (8).

Ahora se me pide que me ocupe de "organización administrativa y relaciones interadministrativas", pero teniendo en cuenta que se cuenta con una Ponencia diferenciada para el "Sector público institucional", lo cual excluye todo el Título III. Quiere decirse con ello que me he de ocupar tan sólo de (una parte) de tres Títulos: el Preliminar, el I y el III.

Como advertencia previa, debo remitir al Dictamen del Consejo de Estado 247/2015, aprobado por la Comisión Permanente el 29 de abril. Un texto de gran calidad intelectual y (lo que es mucho más sorprendente) que se expresa en un tono crítico de extraordinaria crudeza. Parece más el análisis de un profesor universitario con el sentido crítico especialmente agudizado (cosa que, dicho sea de paso, no resulta insólito entre los investigadores granadinos, dotados de manera innata e indeleble de esa cualidad intelectual innombrable que los hace de difícil fungibilidad con los nativos de otros lugares de Andalucía y de España) que la opinión emitida por Alto Cuerpo Consultivo, siempre casi o casi siempre expresada de términos versallescos sobre una iniciativa gubernamental. Más aún si se trata del informe no preceptivo. Se conoce que estamos en el período terminal de una legislatura ("los minutos de la basura", como suele decirse para el final de los partidos de fútbol) y que todos, incluso los más circunspectos, nos vamos sintiendo liberados, quizá incluso de manera inconsciente.

\section{DIAGNÓSTICO}

A estas alturas de 2015, lo primero es preguntarse qué piensa la opinión pública sobre la Administración española. Cuando hablo de opinión pública pienso en la del hombre de la calle, la doxa, y también la del científico o especialista, la episteme. Pues bien, los estudios disponibles, a reserva de lo que voy a decir más abajo, muestran un veredicto unánime: insatisfacción.

Con ello no me refiero sólo ni principalmente a los factores cuantitativos, esto es, el tamaño, medido en el número de empleados públicos, ya sean funcionarios en sentido estricto o no. Los últimos estudios que he podido ver mencionan una cifra entre 2,4 y 2,7 millones. ¿Mucho o poco? Depende, por supuesto, de varios factores, algunos objetivos (cuál sea el parámetro -geográfico o cronológico- de comparación) y otros abiertamente subjetivos, como la ideología de cada quien.

Como ahí estamos en el reino de los valores y por tanto va a ser difícil llegar a conclusiones mínimamente científicas, si queremos avanzar un poco habrá que ir empleando otros criterios, como la disección por sectores o, como se decía antes, por ramos de actividad. Y la demoscopia nos enseña que allí donde la Administración realiza prestaciones materiales, el juicio suele ser esencialmente favorable: educación (con matices); sanidad; y fuerzas y cuerpos de seguridad del Estado. Quizá sea casualidad, pero lo cierto es que se trata de los tres servicios públicos cuyo desempeño resulta intensivo en personal, aunque con la diferencia de que los dos primeros son la quintaesencia del Estado social y el tercero constituye la manifestación típica, y plenamente superviviente, del Estado policial.

El resto es, para decirlo en términos groseramente simplificados, la actividad administrativa que se despliega mediante actos administrativos. Faltan estadísticas fiables (uno de nuestros grandes fracasos como país, por cierto), pero muy probablemente la imagen sea, en efecto, negativa: pura burocracia, descoordinación entre quienes hacen cosas parecidas y sobre todo, politización. A los cuates de los ganadores de las elecciones se los encuentra uno por todas partes, porque los partidos políticos, al margen de los arcangélicos cometidos que les atribuye el Art. 6 de la Constitución, sirven sobre todo de auténticas agencias de colocación: los gabinetes son una verdadera mina, muy codiciada por los partisanos. Y los procesos selectivos no están en modo alguno gobernados por el mérito y la capacidad. Lejos de las oficinas públicas descritas hace más de un siglo por Max Weber, con su funcionamiento rutinizado y por tanto previsible, lo nuestro es el reino del espasmo, casi siempre a impulsos del periódico del día y del lugar. Un horror. 
Pero de lo cualitativo se acaba volviendo a lo cuantitativo y además la patología la acaba reconociendo el mismísimo legislador, aunque sea sólo por referencia a un eslabón de las Administraciones, el local. Sí en diciembre de 2013 se dictó una Ley -inédita por cierto en su aplicación práctica: no ha habido ni una fusión municipal- que predica como objetivo la sostenibilidad y racionalización es porque (al menos de manera implícita) se está condenando el statu quo como insostenible e irracional. Demasiado grande y, por tanto, caro. Con más o menos fundamento (las mayores partidas del gasto público, como el servicio de la deuda, el seguro de desempleo y las pensiones de jubilación, no tienen una relación directa con el tamaño de la Administración), es lo cierto que los españoles sufren -sufrimos- una presión fiscal asfixiante y que tal cosa, aunque últimamente haya podido quizá tener algún alivio parcial y menor, no lleva trazos de remitir, lo cual no es ajeno -y así lo percibe la mayoría- a lo descomunal de las estructuras administrativas o, dicho con más precisión, del mapa de la Administración en el espacio, caracterizado por la superposición histórica de niveles al modo de los estratos geológicos y sin que ninguna adición conlleve una correlativa supresión de nada: a los más de 8.000 municipios de Cádiz (1812) y a la estructura periférica arbitrada por mi paisano Javier de Burgos (1833) se fueron sumando luego las Diputaciones (criaturas discutidas pero rocosas) y, desde 1978-1983, las Comunidades Autónomas, igualmente expandidas por todo el territorio nacional. Lo disparatado y gravoso de dicho modelo, por así llamarle, se solapa con un fenómeno diferente (la crisis del Estado social en los países del sur de Europa), de suerte que uno no acaba sabiendo si el hecho de que el porcentaje del PIB dedicado al sector público sea el 40 por ciento -una patología, a mi juicio- se debe a lo uno o a lo otro. A ver si el viento que parece venir ahora de nuestros vecinos del Norte (el llamado Estado simplemente garante, sobre el cual no procede disertar ahora) tiene como consecuencia favorable que la presión fiscal media sobre las personas físicas deje de estar en el 30 por ciento. Que mientras tanto estemos pudiendo salir de la crisis es la mejor prueba de que las vírgenes de Lourdes y de Fátima velan por nosotros, aunque sea desde fuera de nuestras fronteras.

Al denostado PLRJSP de 2015 hay que reconocerle que no se esconde. La Exposición de Motivos comienza reconociendo una realidad nada buena y que debe ser cambiada y mejorada. Sólo desde la insatisfacción se explican las siguientes afirmaciones:

“El 28 de octubre de 2012 el Consejo de Ministros acordó la creación de la Comisión para la Reforma de las Administraciones Públicas con el mandato de realizar un estudio integral dirigido a modernizar el sector público español, dotarle de una mayor eficacia y eliminar las duplicidades que le afectaban y simplificar los procedimientos a través de los cuales los ciudadanos y las empresas se relacionan con la Administración.

El informe, que fue elevado al Consejo de Ministros el 21 de junio de 2013, formuló 218 propuestas basadas en el convencimiento de que una economía competitiva exige unas Administraciones Públicas eficientes, transparentes, ágiles y centradas en el servicio eficiente a los ciudadanos y las empresas. En esta misma línea, el Programa nacional de reformas de España para 2014 establece la necesidad de impulsar medidas para racionalizar la actuación administrativa, mejorar la eficiencia en el uso de los recursos públicos y aumentar su productividad".

Expuesto lo mismo pero en negativo y más crudo: lo que hoy tenemos es irracional, ineficiente e improductivo. Bien dicho.

\section{TERAPIA 2011-2015}

¿Qué se ha hecho en estos cuatro años de legislatura, supuestamente conducida por la austeridad -palabra casi siempre mal empleada y que, según quien la pronuncie, puede ser un insulto o un elogio- en lo que concierne a mejorar a la Administración, así en lo cuantitativo como en lo cualitativo? Todos sabemos que los impulsos han venido de fuera (de Bruselas y, a su vez, de Berlín), y no de aquí mismo, lo cual por cierto nos debe producir un gran alivio. Pero vayamos al fondo: ¿qué se ha hecho de verdad?

A mi juicio, nada o muy poco, a salvo de la introducción de la famosa tasa de reposición de efectivos (TRE) y de la consiguiente reducción del número de funcionarios en activo. Y es que el problema está en que los citados impulsos de Bruselas tenían un contenido equívoco: sólo exigían la reducción del déficit público. Y sucede que tal cosa es únicamente una diferencia entre dos magnitudes, el ingreso y el gusto, de suerte que la citada reducción se puede conseguir no sólo podando lo segundo, sino también incrementando lo primero. Para un político español de cualquier partido, la elección no ofrece duda. La Administración (y prueba de ello es que el déficit público sigue siendo altísimo) apenas ha cesado de gastar y si acaso lo que ha hecho es dejar de pagar, que es cosa distinta y mucho peor.

Y si ponemos el foco en la flexibilización de los modos de la Administración (obligada, sin duda, desde la Directiva de servicios de 26 de diciembre de 2006), convendremos en que todo sigue igual de mal: desde diciembre de 2011 no se ha hecho mucho más que en la legislatura anterior cuando en noviembre y diciembre de 2009 se aprobaron, para aparentar seriedad, las dos normas legales cosméticas que ya conocemos. 
Por supuesto que entre diciembre de 2011 y junio de 2015 el BOE no ha dejado de verse surtido. En no pocas ocasiones, con medidas que, al menos indirectamente aunque con mucha efectividad, inciden sobre la organización administrativa y obligan a su adelgazamiento. Me refiero sobre todo a los Reales Decretos-Leyes que, con objeto inmediato en el Fondo de Liquidez Autonómica o el Plan de Pago a Proveedores, y del todo al margen de la Ley Orgánica de Financiación de las Comunidades Autónomas, han tenido como consecuencia que el grueso del stock de deuda pública territorial haya terminado cayendo en manos del Estado, que ha pasado así a disponer de unos instrumentos de control muchos más poderosos que los (teóricamente mortíferos, pero en realidad romos) se autoatribuyó mediante la controvertida, y en el fondo muy ingenua, Ley Orgánica de Estabilidad Presupuestaria de 2012.

\section{EL PROYECTO DE LEY DE 2015}

¿Se aborda ahora por fin el problema? No. O de manera muy insuficiente. En teoría, el remedio legal está en la electrificación total, aun a riesgo de sufrir calambrazos, pero me temo que por sí solos Volta y Galvani no van a llevarnos al país 3.0 que necesitamos (y que, en parte, y a trompicones, vamos en buena hora teniendo por impulsos europeos). A ver si la crisis griega, que amenaza con cronificarse, tiene como efecto que la integración europea se intensifique y Bruselas deje cada vez menos margen a nuestros políticos.

Algunas ideas concretas en el ámbito que nos ocupa, que es el de la organización y las relaciones interadministrativas:

1) Sobre los órganos, lo primero que hay que decir es que el Art. 5.1 sigue manteniendo una noción restrictiva: sólo lo serán aquellos "a los que se les atribuyan efectos jurídicos frente a terceros, o cuya actuación tenga carácter preceptivo".

Estamos por tanto ante una especies. El genus es el del Art. 31, apartado 1: "Las unidades admisnistrativas son los elementos organizativos básicos de las estructuras orgánicas". De hecho, el Art. 34 contiene reglas sobre creación, modificación y supresión de órganos administrativos.

Pero son reglas -provenientes de la LOFAGE de 1997: Arts. 5 y 7, respectivamente- puramente formales, porque los criterios de fondo y más rigurosos -el sabio consejo de Guillermo de Occam: Entia non sunt multiplicanda sine necessitate- quedan al margen. "No podrán crearse nuevos órganos que supongan duplicación de otros ya existentes si al mismo tiempo no se suprime o restringe debidamente la competencia de éstos. A este objeto, la creación de un nuevo órgano sólo tendrá lugar previa comprobación de que no existe otro en la misma Administración Pública que desarrolle igual función sobre el mismo territorio o población". Nadie discutirá que la intención es buena.

2) De los Convenios -todo un clásico en nuestro Estado de las Autonomías, sobre todo si se trata de levantar nuevas infraestructuras y hay que repartirse el coste- se ocupa el nuevo texto con profundidad y con ánimo (inducido por el Tribunal de Cuentas desde 2010, como es sabido) de juridificarlos, es decir, de poner orden desde esa muy concreta perspectiva.

De la figura - "los acuerdos con efectos jurídicos adoptados por las Administraciones Públicas, las entidades y organismos públicos vinculados o dependientes o las Universidades entre sí o con sujetos de derecho privado"- se predica, por el apartado 1 del Art. 23, un lugar intermedio entre dos cosas. Por arriba, "Ios Protocolos Generales de actuación o instrumentos similares que comporten meras declaraciones de intención de contenido general o que expresen la voluntad de las Administraciones y partes suscriptoras para actuar con un objetivo común, siempre que no supongan la formalización de compromisos jurídicos concretos y exigibles". La otra delimitación, la que se realiza por abajo, tiene por diana los contratos en sentido estricto: "Los convenios no podrán tener por objeto actos de contenido jurídico ni prestaciones propias de los contratos ni mandatos de gestión regulados en la legislación de contratos del sector público". De "los convenios que tengan por objeto dichas prestaciones" se predica que "se regirán por los principios y reglas contenidos en la legislación de contrato del sector público".

Esa difícil posición intermedia -tienen efectos jurídicos pero su objeto no son actos de contenido jurídico- es en efecto la que se reserva para los Convenios. Acerca de los cuales se satisface además el tributo obligado a la dogmática: no pueden suponer "cesión de la titularidad de la competencia ni de los elementos sustantivos de su ejercicio" (Art. 22.1). Y también otro peaje: el de la (supuesta) soberanía del legislador presupuestario. Es el Art. 25.3: "Cuando los convenios plurianuales suscritos entre Administraciones Públicas incluyan aportaciones de fondos por parte del Estado para financiar actuaciones a ejecutar exclusivamente por parte de otra Administración Pública y el Estado asuma, en el ámbito de sus competencias, los compromisos frente a terceros, la aportación del Estado de anualidades futuras estará condicionada a la existencia de crédito en los correspondientes presupuestos". 
De la indicada voluntad de juridificación son reflejo los Arts. 26, Extinción de los convenios, y 27, Efectos de la resolución de los convenios. Es evidente la influencia de lo establecido, con mayor o menor fortuna en la práctica, para los contratos públicos.

Y dándole al Tribunal de Cuentas el estatuto propio de un buzón de Correos (Art. 28).

3) De la Administración del Estado se predican en el Art. 29.1 algunos principios demasiado generales. Por un lado, el de descentralización funcional (en abierta contradicción con los límites, bien sanos, establecidos más abajo para la creación de nuevas entidades institucionales). Por otro los (más tradicionales, aunque no menos infelices) de "desconcentración funcional y territorial”.

La mejor prueba de que todo ello no pasa de ser mera palabrería (gracias a Dios) es lo que el lector se encuentra a continuación, que no puede ser más rancio, jerarquizado y centralizado: Ministro (Art. 36), Secretario de Estado (Art. 37); Subsecretario (Art. 38); Secretario General (Art. 39); Secretario General Técnico (Art. 41); y, por fin -ahoga tanto Secretario-, Director General (Art. 41). Como siempre. Por encima del Ministro no hay nadie, porque se conoce que los poderes presidenciales de dirigir la acción del gobierno -la Richtlinienkompetenz del Canciller federal alemán- es algo que, aun proclamado en el Art. 98 de la Constitución, carece de la menor existencia real, al menos en el plano de lo administrativo.

El lector avezado sabe bien de lo que estoy hablando: el Art. 97 de la Constitución declara, sí, que el Gobierno dirige la política (interior y exterior), pero el precepto siguiente establece otra cosa: que es el Presidente el que a su vez dirige la acción del Gobierno ( $y$, por lo común, también de un partido). ¿En qué consiste ese cometido? De hecho, en bastante más que las funciones, meramente formales cuando no protocolarias, que enumera con ánimo cansino el Art. 2 de la otra Ley de 1997, la del Gobierno.

4) De las relaciones interadministrativas, para terminar, se ocupa el muy escuálido Título III. Es el reino, de entrada, de las declaraciones generales y platónicas, que se sitúan completamente al margen de nuestra politizada y partidista vida pública: Arts. 115 y 116. Y también de las clasificaciones dogmáticas: entre las "relaciones de cooperación" se distinguen a) las que no tienen apellido (funcionales, para entendernos), que están en los Arts. 118 y 119 y b) las orgánicas de los Arts. 120 a 129, que, como era de esperar, vuelven a ser las famosas Conferencias, casi siempre sectoriales y multilaterales.

Pero no podía faltar (el paciente lector de estas líneas seguro que ya lo estaba echando en falta) una regulación sustantiva de las “Relaciones electrónicas entre las Administraciones”: Art. 130 a 133. De hecho, el (nuevo) Registro estatal de Órganos e instrumentos de cooperación que se regula en la Disposición Adicional Octava se llama "electrónico". Y efectivamente lo es.

Lo dicho: con el PLRJSP parece que lo que sí vamos a tener una Administración electrónica o, al menos, electrificada. Todo un consuelo.

Pero tengo la impresión de que el autor del texto -que sigue teniendo en la cabeza a los actos administrativos y poco más- no ha pensado en una Administración moderna. Y ni tan siquiera ha fotografiado la Administración que, pese a todo, y a trompicones, vamos teniendo ya. Que no es sólo la del Estado prestacional (que también: volvemos a lo dicho al inicio sobre educación y sanidad), sino, cada vez más, al menos en materia económica, la de regulación y dirección. Una Administración que vive en un contexto europeo como el pez tiene su hábitat dentro del agua. En eso (que sólo de vez en cuando aflora, sí, en esta Ley) el PLRJSP no está en la avanzadilla, para decirlo con palabras suaves. Más suaves que las empleadas por el Consejo de Estado en su Dictamen 247/2015. 